\title{
The Development of Sociolinguistic Diglossic Knowledge in Oral-Literacy Mismatch Situations: Preliminary Findings from Palestinian Arabs
}

\author{
Baha Makhoul1,2, Thuraia Copti-Mshael1,2, Reem Khamis Dakwar ${ }^{3}$ \\ ${ }^{1}$ Oranim Academic College for Education, Kiryat Tiv'on, Israel \\ ${ }^{2}$ CET-The Center for Educational Technology, Tel-Aviv, Israel \\ ${ }^{3}$ Adelphi University, New York, USA \\ Email: Baham@cet.ac.il
}

Received 28 April 2015; accepted 25 July 2015; published 29 July 2015

Copyright (C) 2015 by authors and Scientific Research Publishing Inc.

This work is licensed under the Creative Commons Attribution International License (CC BY). http://creativecommons.org/licenses/by/4.0/

(c) (i) Open Access

\begin{abstract}
This study explores the explicit sociolinguistic knowledge and awareness of Arabic diglossia of forty Palestinian children in Israel, ages 6:11 - 11:3 using the Diglossic Knowledge and Awareness Questionnaire, a subtest of the Arabic Diglossic Knowledge and Awareness Test (ADAT). Central to this approach is the recent insight that children who are learning to read and write in a language that is mismatched to their spoken language at home (referred to as an oral-literacy mismatch) need to develop linguistic awareness for both systems, as well as the relationship between them (Terry, Connor, Thomas-Tate, \& Love, 2010; Terry, 2011). Our preliminary findings indicate that during third and fourth grades children develop the ability to define the two language varieties that exist in Arabic diglossia, and are able to report on their explicit knowledge of phonological and lexical interrelationships between the two linguistic systems. Furthermore, our findings also indicate that by the third grade the Modern Standard Arabic (MSA) variety is given a higher status by those children along with reports of its superiority and purity. These findings suggest a need to take into consideration this developmental milestone in any educational and clinical evaluation of children with and/or at risk to have learning and/or reading disabilities in diglossic language environments, such as Palestinian Arab students in Israel.
\end{abstract}

\section{Keywords}

Palestinian-Spoken-Arabic (Ammyia), Modern Standard Arabic (Fusha), Diglossia, Sociolinguistic Awareness, Emergent Literacy, Oral-Literacy Mismatch 


\section{Introduction}

All Arabic speaking children grow up in communities characterized as being diglossic speech communities, in which two language varieties coexist side by side: the "Low" variety (spoken Arabic known as Aammyia) and the "High" variety (modern standard Arabic known as Fusha). All spoken Arabic, "Low variety" includes the Palestinian Arabic (PA), are used in daily communication, and therefore are learned at home and in the community. However, the Modern standard Arabic (MSA), Fusha, "High variety" is learned explicitly and it is represented in written text and used in formal contexts. Generally, children acquire the "Low variety", or spoken dialect, via implicit learning mechanisms. Yet the use and the intensive exposure to the high language variety start once the children enter school, as part of a formal education. This "diglossic" (Ferguson, 1959) situation is exhibited in multiple other speech communities (e.g., Swiss German in Switzerland), but has been generally marginalized in the study of language and literacy skills (e.g., Labov, 2003).

\subsection{Diglossia}

1. Function: A defining feature of diglossia refers to functionally specialized and slightly overlapped use of the two language varieties (Ferguson, 1959: p. 328). For example, in Arabic, the High variety is used in formal speech in a church, mosque, parliament or formal conversations; while the Low variety is used for folkloric songs and daily conversations (Holes, 2004). Similarly, in the United States, for speakers of African American English, Standard American English, or SAE is considered as a dominant dialect used in governmental communications, national television broadcasts, and many businesses; however, the spoken African American English( AAE) is used for popular culture and daily communications at home for those raised in AAE speaking families (Pearson et al., 2013).

2. Prestige: This second defining feature refers to the observation that in diglossic communities, the High language variety $(\mathrm{H})$ is perceived to be superior to the Low language variety $(\mathrm{L})$ in many respects. Perception of MSA as more sacred and beautiful than the (L) variety has been extensively documented in Arabic (see Haeri, 2003). In the case of AAE, this relationship of unequal and stigmatized status has been similarly documented, in spite of the current recognition of AAE by various legal and professional societies (e.g., see Pearson et al., 2013). "In the case of a minority speech community in the U.S., White-American proper English (i.e., the standard English) is the high dialect which is approved for education, jobs, and communication with 'outsiders'. The mother tongue of the minorities (e.g., Black English) is the low dialect for everyday life in the family and community" (Ogbu, 1999: p. 151).

3. Literary Heritage: In diglossic communities, written literature is predominantly written in the $\mathrm{H}$ variety and "held in high esteem by the speech community" (Ferguson, 1959: p. 331). In the same way, literature in the U.S. is predominantly written in SAE, and in MSA in the Arab world.

4. Acquisition: Based on Ferguson (1959), the Low and High language varieties are acquired differently. The Low variety is acquired naturally as a mother tongue, whereas the High variety is "chiefly accomplished by the means of formal education”, explicitly in terms of rules (Ferguson, 1959: p. 331). In Arabic, the spoken dialect is acquired naturally and considered to be the mother tongue for Arabic speaking children (Khamis-Dakwar \& Makhoul, 2014). In the same way, "AAE is the native language variety for many, but not all, African Americans (Pearson et al., 2013: p. 32) acquired naturally at home within their community, whereas SAE is acquired once they are exposed to Standard English in school” (e.g., Willis, 2004).

5. Standardization: High language varieties in diglossic situations are subjected to processes of standardization, in terms of spelling, grammar and usage that are not typically applied to Low language varieties by members of the speech communities. Actually, in the Arab world, traditional grammarians determined that MSA was the only language worthy of analysis and excluded spoken dialects from their inquiry; this reflects the view that spoken Arab dialects are considered "bad" languages, and led to a situation where—until fairly recently—spoken Arabic was mainly studied by Western scholars (e.g., Elgibali, 1996). Similarly, the AAE language has been described as "a restricted, deficient code" (Pearson et al., 2013: p. 32). Despite advancements in the study and standardization of spoken Arabic dialects and AAE, Arabic dialects are still understudied and "AAE is still most often characterized, not as a system, but as a list of 30 or more distinguishing features that focus on isolated properties of the variety” (Pearson et al., 2013: p. 32).

6. Stability: Diglossia is a stable situation that might persist for centuries. According to Ferguson's observation, “Arabic diglossia seems to reach as far back as our knowledge of Arabic goes” (Ferguson, 1959: p. 233). 
Similarly, AAE is a systematic and rule governed system that outgrew from many languages of West Africa (see Pearson et al., 2013) and has coexisted with various regional dialects of English in America, over at least the past hundred years.

The last three characteristics (7 - 9) of diglossic language situations as characterized by Ferguson (1959) are grammar, lexicon, and phonology. Ferguson refers to the presence of extensive grammatical differences between the Low and High varieties in diglossia (Ferguson, 1959: p. 333), and that some words bearing the same meaning may differ phonologically between language varieties, to the extent that these phonological differences may indicate which variety is being used. Lastly, according to Ferguson "L phonology is the basic system and the divergent features of $\mathrm{H}$ phonology are either a subsystem or a parasystem” (Ferguson, 1959: p. 335). Such differences between the Low and High language varieties in Arabic (see Al-Toma, 1969) and between SAE and AAE (see Roseberry-McKibbin, 2008) have been documented in the literature.

While acknowledging the specificity of each diglossic situation to each speech community, and recognizing that some may still debate the diglossic status of AAE/SAE, we suggest that there are clear parallels between diglossia in Arabic and in AAE/SAE. Both situations exhibit parallel oral and written linguistic mismatches, as children speaking the Low variety are expected to code and decode a written system that does not match their native linguistic variety. We suggest that linguistic mismatch between informal spoken variety and the formal variety used in reading and writing would be underpinned by common cross-situational developmental diglossic milestones in the course of language learning development. This approach is based on the fact that spoken language is a biological specialization that all humans are hard-wired to acquire naturally, but written language is largely a cultural invention reliant "on oral language skills that underpin the acquisition of reading” (Goswami, 2008: p. 136).

\subsection{The Development of Diglossic Knowledge and Awareness in Oral-Literacy Mismatch Situations}

A number of studies have already focused on researching language and literacy performance in typically developing children from various speech communities exhibiting diglossia (e.g. Palestinian Arabic speakers in Israel, African American English speakers in the United States, and Cypriot Greek speakers in Cyprus) (For a review, see: Harris \& Schroeder, 2013; Khamis-Dakwar \& Makhoul, 2014). Collectively, these studies have accumulated evidence showing that linguistic and metalinguistic performances of children in oral-literacy mismatch situations differed relative to whether the examined linguistic feature and/or emergent literacy skill is exhibited similarly or differently in the two language varieties. Hence, it is presumed that in oral-literacy mismatch situations, knowledge of and awareness to the two linguistic varieties and the interrelationship between them at the different linguistic levels (i.e., semantic, phonological, morphosyntactic, and pragmatic) is part of the typical advanced language for learning developmental milestones in these specific sociolinguistic situations. Moreover, studies of language and literacy development in mismatch situation show that enhanced diglossic knowledge and awareness (referred to as "linguistic flexibility" or "linguistic awareness") correlates with increased ability to switch between the two language varieties and/or with successfully learning to read and write in the high language variety (e.g., Terry, Connor, Thomas-Tate, \& Love, 2010; Terry \& Scarborough, 2011; Pittas \& Nunes, 2014) and that third grade typically developing African American children speakers of AAE were found to be able to switch between the two language varieties depending on the context (i.e. reading and writing versus oral communication) (Craig, Thompson, Washington \& Potter, 2003; Thompson, Craig, \& Washington, 2004).

Consequently, it has been found that the most effective approaches toward academic success of AAE speaking children are not only those that cherish diversity and hold a high level of expectation from all students, but that first and foremost are linguistically informed in their design. Linguistically informed approaches in this context refers to any educational approach in which correspondence between the two language varieties is highlighted, along with teachers' training to develop their awareness of the effects of diglossia on learning, in conjunction with explicit facilitation towards students' understanding of the two varieties and the interrelationship between them (for a review see Pearson et al., 2013).

There are few published studies on literacy development and diglossia in Arabic-speaking communities. Research that do exist on this specific sociolinguistic situation focuses mainly on Palestinian Arab children living in the state of Israel. The Palestinian community in Israel comprises 20.7 percent of the Israeli population (Central Bureau of Statistics, 2013). Members of the Palestinian community in Israel speak Palestinian Spoken 
Arabic as a native language, and share cultural values and practices. Palestinian children in Israel are expected to attend Arab schools. They acquire their spoken dialect as their mother tongue, and their exposure and/or use of MSA is intensified mainly upon school entry, as it is the language variety used in textbooks and curriculum and for some formal communications. It is assumed that the effect of Arabic diglossia on linguistic skills and literacy achievement would be the most apparent in the Palestinian community in Israel in comparison to Arab speech communities within the Arab world. This is in part due to the institutionalized, decreased exposure to MSA (in the state of Israel, in comparison to the Arab world, as well as the lower status of Arabic as the language of the indigenous minority in Israel, and the high poverty rate of Palestinian children in Israel (Coursen-Neff, 2004). Several linguistic studies have documented the distinctive features of spoken Palestinian Arabic in comparison to MSA in all language domains (for a review, see Saiegh-Haddad \& Henkin-Roitfarb, 2014) and have demonstrated that the difference (i.e. mismatch) between the two language varieties of Arabic significantly affects language for learning performances of typically-developing Palestinian children in Israel at the phonological and lexical level (Saiegh-Haddad, 2003, Saiegh-Haddad, 2004, Saiegh-Haddad, 2005, Saiegh-Haddad, Levin, Hende \& Ziv, 2012), morphosyntactic level (Khamis-Dakwar, Gordon \& Froud, 2012) as well as narrative development (Leikin, Ibrahim, \& Egbaria, 2013). However, we argue that these findings are not incorporated in the educational learning and reading assessments of students in Arabic (For a review, see Khamis-Dakwar \& Makhoul, 2014).

An extensive review of language assessment tools that has been developed in Israel, attempting to identify children with learning difficulties and disabilities in the clinical field, address the linguistic knowledge and literacy skills that are specific to literary Arabic, thus failing to convey the impact of Arabic diglossic nature on Arabic speakers' linguistic knowledge and their lexicon, calling into question its diagnostic adequacy. Accordingly, the development of verbal and linguistic tests should strive to accurately conceptualize the linguistic capacities and literacy skills of Arabic speakers, underlying reading and writing acquisition. Furthermore, the existing didactic diagnostic tools lack standardized comprehensive assessment of several linguistic capacities that are ultimately subject to subjective evaluation of the diagnostician based on performance across tasks. In addition, several tasks are based on diagnostic tasks that are developed for Hebrew speakers, impacting assessment validity. Ultimately, none of the available assessment tools addresses the children's diglossic knowledge, neither explicitly nor implicitly.

Examination of diglossic awareness within learning assessment is crucial in light of the fact that the Arabic teaching curriculum is based on the communicative holistic approach to teaching Arabic, and is not linguistically informed in relation to diglossia (i.e. it disregards teaching Arabic grammar and lacks explicit teaching of diglossic knowledge and awareness). More specifically, the currently used 2009 elementary school Arabic teaching curriculum, presented by the Ministry of Education in Israel focuses on listening, speaking standard language, reading different text types, and writing linguistically sound texts to different recipients and different purposes, in addition to processing and using different linguistic structures through the use of Al-Ra'id (The Pioneer) textbook for teaching Arabic at the elementary level (through sixth grade) in which most of the interactions in the classroom are conducted using the spoken dialect (Israeli Ministry of Education curriculum, 2009: p.13). Lack of designed focus on explicit teaching of diglossic knowledge and awareness (keeping in mind its documented correlation with success in learning to read and write in similar situations (i.e. African American English and Cyprus Greek) (Terry, Connor, Thomas-Tate, \& Love, 2010; Terry \& Scarborough, 2011; Pittas \& Nunes, 2014) highlights the need to incorporate evaluation of diglossic knowledge and awareness in the evaluation of students at risk and/or with reading and learning disabilities as a basis for appropriate intervention plan sensitive to the needs of a student learning to read and write in a diglossic situation.

This particular study aims to examine the progression of explicit diglossic sociolinguistic knowledge in first through fifth grade typically developing Palestinian Arabic speaking children living in a mixed ethnicity town in Israel, using ADAT explicit knowledge subtest (Khamis-Dakwar \& Makhoul, 2014). More specifically, we are inquiring to know at which stage typically developing children are able to explicitly define the two language varieties of Arabic, and what is the order of their explicit understanding of the interrelationship between the two systems in light of its importance in successfully learning to read and write in a standard variety (as evidenced by the reviewed studies on AAE speaking children learning in SAE schools), while lacking linguistically informed curriculum with no systematic lesson plans or facilitation toward this sociolinguistic diglossic awareness. We hope this foundational knowledge can be incorporated in future assessments of at risk students in order to 
develop language learning disabilities in Arabic.

To examine children's explicit sociolinguistic knowledge and awareness to diglossia, we tested a group of 6 to 11 year old Arabic speaking children using ADAT's diglossic knowledge and awareness questionnaire. In this paper, we are interested in examining the development of sociolinguistic knowledge directly at the explicit level (i.e. a level that incorporate conscious awareness) of children with no environmental , educational or individual risks to have language learning disabilities in order to identify the developmental milestone in which a student is expected to develop diglossic knowledge and awareness. Hence, Palestinian children, speakers of the spoken Arabic dialect (Aammyia), whom were selected to participate in this study were children with typical sociolinguistic development and no learning disabilities, they attended a church-run school that uses Al-Rai'd textbook and lived in an Arab-Jewish mixed town.

\section{Method}

A questionnaire that is a subtest of the newly developed ADAT was administered to gather information regarding children's explicit knowledge of and awareness to the diglossic sociolinguistic situation of their speech community. The questionnaire consists of eight questions addressing a child's explicit knowledge of diglossia, literacy texts preferences, and cognitive processes related to reading and writing.

\subsection{Participants}

Forty native Palestinian-Arabic language speaking, first through fifth grade, children from moderate-high socioeconomic status were recruited to participate in the study at their school in Haifa, a mixed Arab-Jewish city in the northern part of Israel. All participating children had been exposed to MSA through formal instruction in school. There were twenty girls and twenty boys, ranging from six years and 11 months to 11 years and three months. None of the participating children had hearing, health, behavioral, or developmental deficits, based on reports from parents and teachers. The children were divided into five grade/age groups of eight children each: 1st grade (i.e. age of six years and 11 months old to seven years and 10 months old), 2nd grade (age of seven years and six months old to eight years and one month old), 3rd grade (age of eight years and six months old to nine years and 10 months old), 4th grade (age of nine years and eight months old to 10 years and five months old), and 5th grade (age of 10 years and eight months old to 11 years and three months old) (See Table 1).

All participating students were native speakers of Arabic as a first language, learners of Hebrew as a second language and English as a foreign language, and in addition, they were being taught Modern Standard Arabic using the Al-Rai'd (The Pioneer) textbook for elementary school.

\subsection{Materials}

A questionnaire that is part of the newly designed test entitled "Arabic Diglossic Knowledge and Awareness Test” (ADAT) was used in this examination (see Khamis-Dakwar \& Makhoul, 2014). The questionnaire includes eight questions presented in the spoken dialect of the child, the questions aimed to seek information about; the student's explicit knowledge of the language variety in Arabic diglossia, the interrelationship between fusha (MSA) and ammiya (PSA), text preferences, and cognitive processes related to the interplay between diglossia and learning to read and write. As per the tests' directions, children's responses were transcribed at the time of administration and analyzed later.

The ADAT had previously been piloted with 40 children in another church-run school in Nazareth, and has been modified to include a coding scheme based on pilot results (see Khamis-Dakwar \& Makhoul, 2014). Pilot administration also evaluated the test's face and content validity.

The first two questions in the questionnaire ask about the child's knowledge of the terms fusha and ammiya

Table 1. Means and standard deviation of ages in months by each grade level.

\begin{tabular}{ccccc} 
& First grade & Second grade & Third grade & Fourth grade \\
\hline Mean age & 87.75 & 93.38 & 107 & 123.13 \\
(Standard deviation) & $(3.58)$ & $(2.33)$ & $(5.35)$ & 131.38 \\
\hline
\end{tabular}


and the main defining features of these two terms (i.e., functional distribution).

Q1: Do you know that in Arabic there is a fusha and ammiya? What are these two?

Q2: When do we use each one of those? Can you give me an example of when do you use fusha and when do you use ammiya ${ }^{1}$ ?

The third and fourth questions inquire about children's awareness of the interrelationships between the two language varieties (i.e., differences and similarities between the two varieties).

Q3: Are there any differences between these two languages? Can you give me some examples?

Q4: Are there any commonalities between these two languages? Can you give me some examples?

The fifth question inquires about the students' awareness of the challenges related to reading and writing in the standard variety.

Q5: Do you at times feel it is hard for you to understand fusha? If you do feel it is hard, is it harder for you when you hear it or when you read it?

The sixth question examined the children's awareness to texts preferences:

Q6: Which texts do you like to read?

In case a child is unable to answer this question or provides an irrelevant answer, the administrator would prompt the child by asking if s/he likes to read a story or a scientific paper or poems.

Lastly, the seventh and eighth questions address the children's insight to the cognitive load involved in reading and writing in a language that does not match their home language:

Q7: Do you like writing in fusha or just speaking it?

Q8: When you are about to write about a specific topic, do you think about the topic in fusha and write it directly in fusha or do you think about the topic first in ammiya and later writing it in fusha?

A list of the questionnaire questions and the test-coding matrix is provided in Appendix 1.

\subsection{Procedure}

As a preliminary stage, doctoral student was trained by the authors of the study in language development, language testing, and Arabic diglossia, with a special emphasis on ADAT administration and coding guidelines (which includes the questionnaire presented in this paper). The experimenter visited the school twice before commencing the experiment. During these visits the experimenter introduced herself to the children in all participating grades. This was aimed to establish mutual familiarity. Parent questionnaires and consent forms were sent to all parents in the participating classes. On following visits, participating children were randomly selected from a pool of children who had their parents' consent to participate in the study, the participants were within and above average performance in class based on teacher's report, and had no reports of hearing, health, behavioral, or developmental problems, based on parents' and teachers' reports.

Each child was approached individually and was invited to participate in the study in a separate room. The children participated voluntarily in the experiment. The participants were informed that they would be asked a few questions and that their answers would help researchers to understand how language and literacy develop in children with good language and academic performances. They were also told that the study could eventually enable teachers to help children with difficulty in learning how to read and write. The participants were also informed that they could end their participation in the study whenever they wanted to, with no consequences. The questionnaire had no supplementary materials; the experimenter was simply instructed to ask the questions in the spoken Palestinian Arab dialect as transcribed in the written questionnaire.

Materials

The full ADAT consists of five parts (for reviews see Khamis-Dakwar \& Makhoul, 2014). The first part was the explicit diglossic knowledge and awareness subtest presented in this study, as previously explained. The questionnaire-based interaction lasted from 10 to 15 minutes.

The responses were grouped by age and coded, based on the latest ADAT coding taxonomy for quantitative analysis. ADAT coding taxonomy assigns a numerical value $(0,1$, or 2$)$ to reflect the relevance and completeness of the answer. The answers of questions $(1-4,6)$ were coded as full answer (2), partial answer (1) or irrelevant /lack of answer (0). An answer was considered full if a child could do the following; define ammiya and fusha, express their differential contexts of use, the similarities and differences between them with examples,

${ }^{1}$ It should be noted that the terms fusha and Ammiya are common terms used in Arab communities and are not specialized knowledge, the way AAE and SAE are in English. 
and their preferable text type in each question, respectively. Partial answers consisted of children's explanation of only one of the language varieties, the context of use of only one of these varieties, similarities and differences with no examples, or examples with no generated postulation and knowing which texts s/he likes only with prompting for each relevant question. 'Irrelevant answer' refers to child's lack of stated knowledge or vaguely stated knowledge of fusha-ammiya, its functional distribution, its interrelationship, or the type of preferable texts after prompting.

For the fifth question, children's responses were categorized and coded as follows: reported awareness to the effects of diglossia on reading and writing with no reported challenges in processing fusha (2), reported challenges with no reported awareness to the effects of diglossia on reading comprehension and writing (1), no reported challenges with no reported awareness to the potential effects of diglossia (0). Question seven responses were coded as follows: child reports to like BOTH writing and speaking in fusha (2), child reports EITHER writing or speaking fusha (1), child reports not liking to write or speak in fusha (0). For the last question, three types of responses were coded: thinking and writing directly in fusha (2), thinking in ammiya and writing in fusha (1), irrelevant answer (0). The coding matrix for each question is provided in Appendix 1.

\subsection{Data Analysis}

Children's responses were later coded and analyzed into response categories: definition, interrelationship, text preferences, and cognitive processes. Two tokens were presented for the first two categories, one token for text preference, and three tokens for awareness to cognitive processes. Definition category included responses to Q1 and Q2, Interrelationship included responses to Q3 and Q4, text knowledge for Q6, and cognitive processes were Q5, Q7 and Q8.

Kruskal-Wallis $\mathrm{H}$ tests (the non-parametric equivalent to a one-way, between groups ANOVA) for independent samples were conducted to determine whether there were differences in ADAT performances depending on grade and category. In addition, thematic analysis (e.g., Braun \& Clarke, 2006) was used to analyze children’s responses qualitatively.

For the qualitative analysis, all children's responses were categorized according to the following: defining features expressed in Q1 (subcategories: context, attitudes, and users), type of contexts addressed in Q2 (subcategories: school-related, literacy-related, adds and TV related), type of similarities addressed in Q3 (subcategories: phonological, lexical, morphosyntactic, and pragmatic), type of differences addressed in Q4 (Subcategories: phonological, lexical, morphosyntactic, and pragmatic), kind of perceived challenges understanding fusha in Q5 (subcategories: reading, writing, or reading and writing ), type of text preferred by child in Q6 (subcategories: narrative, poems, scientific paper), preferred modes of fusha use in Q7 (Subcategories: writing, speaking, or speaking and writing), translation in writing in Q8 (subcategories: fusha to fusha, or ammiya to fusha), all in order to document specific changes relevant to diglossic knowledge and awareness with increased grade level. A category was described as general if it was stated by all participants in a specific grade level, typical if it applied to 4 - 7 students in each grade. Moreover, it was described as variant if it applied to 2 - 3 cases. Categories that were applied to only one case were dropped.

\section{Results}

Results of the ADAT explicit diglossic knowledge and awareness subtest are reported in Table 2 and Table 3. Mean correct responses for each question within its corresponding category (definition, interrelationship, text preference, and cognitive processes) and each grade level, are given in Table 2. Results of children's total responses and total responses in each category at each grade level are reported in Table 3.

Kruskal-Wallis $\mathrm{H}$ tests revealed significant between-group differences only for overall score, definition questions, and interrelationship questions as shown in Table 3 (for total score $\chi^{2}(4)=11.47$, $\mathrm{p}<0.05$; for definition $\chi^{2}(4)=10.11, \mathrm{p}<0.05$, and for interrelationship $\left.\chi^{2}(4)=11.30, \mathrm{p}<0.05\right)$. No significant differences between the performances of children in the five grades were found for text knowledge $\left(\chi^{2}(4)=7.48\right.$, p $\left.>0.05\right)$, or awareness to cognitive processes $\left.\chi^{2}(4)=8.62, \mathrm{p}>0.05\right)$

These findings reveal that Arabic speaking children in this study showed increased explicit sociolinguistic knowledge of Arabic diglossia with a noticeable change at the third grade level, which echoes similar findings in typically developing African American children speakers of AAE who also showed an ability to switch between the two language varieties in third grade. Interestingly, children's text knowledge and awareness to cognitive 
Table 2. Mean response to questions of the explicit diglossic knowledge and awareness subtest of the ADAT by category and grade level.

\begin{tabular}{ccccccccc}
\hline & \multicolumn{2}{c}{ Definition } & \multicolumn{2}{c}{ Interrelationship } & \multicolumn{2}{c}{ Text knowledge } & \multicolumn{2}{c}{ Awareness to cognitive processes } \\
\cline { 2 - 9 } & Q1 & Q2 & Q3 & Q4 & Q5 & Q6 & Q7 & Q8 \\
\hline Grade1 & 0.50 & 1.00 & 0.63 & 0.63 & 1.00 & 1.13 & 0.88 & 0.87 \\
Grade 2 & 0.75 & 0.88 & 0.75 & 0.25 & 2.00 & 1.75 & 0.88 & 1.50 \\
Grade 3 & 1.13 & 1.75 & 1.50 & 1.50 & 1.87 & 1.75 & 1.25 & 1.25 \\
Grade 4 & 1.25 & 1.25 & 1.50 & 1.25 & 1.25 & 2.00 & 1.25 & 1.25 \\
Grade 5 & 1.50 & 1.75 & 0.88 & 1.38 & 1.50 & 1.88 & 1.13 & 1.38 \\
\hline
\end{tabular}

Table 3. Mean total responses for definition questions, interrelationship questions, and cognitive processes questions within each grade level.

\begin{tabular}{|c|c|c|c|c|c|c|}
\hline & Grade 1 (M) & Grade 2 (M) & Grade 3 (M) & Grade 4 (M) & Grade 5 (M) & $\mathrm{K}-\mathrm{W} \chi^{2}(4)$ \\
\hline Definition & 0.75 & 0.81 & 1.44 & 1.25 & 1.63 & $10.11^{*}$ \\
\hline Interrelationship & 0.63 & 0.50 & 1.50 & 1.38 & 1.13 & $11.30^{*}$ \\
\hline Text knowledge & 1.00 & 2.00 & 1.88 & 1.25 & 1.50 & 7.48 \\
\hline $\begin{array}{c}\text { Awareness to cognitive } \\
\text { processes }\end{array}$ & 0.96 & 1.38 & 1.42 & 1.50 & 1.46 & 8.62 \\
\hline Overall Score & 0.83 & 1.09 & 1.50 & 1.38 & 1.42 & $11.47^{*}$ \\
\hline
\end{tabular}

processes were not significantly different with grade levels.

\subsection{Qualitative Analysis}

\subsubsection{Categories for Domain 1: Definition of the Two Language Varieties of Arabic}

Kindergarten and first graders generally were not able to consciously define the two language varieties of Arabic without prompting. Third through fifth graders were typically able to report on the functional distribution of the two language varieties in terms of contexts of use. Another variant observed in the responses of third-fifth graders is the incorporation of the superior attitude towards fusha in the definition of the two language varieties. For example, a fifth grader said in response to Q1 "The fusha language is the language of our ancestors, it is the mother tongue, and the correct language to use in literature". A first grader pointed out "We speak with one of these, but it is more correct in fusha. In the ammiya we include foreign words".

\subsubsection{Categories for Domain 2: Interrelationship between Two Language Varieties}

The data reveals that it was typical for participants from all grades (except 1st grade) to report awareness to differences between the two Arabic varieties (fusha and ammiya), mainly on the phonological and lexical level. One participant from first grade provided the following answer in relation to differences between the two varieties: "When I say ma?ass I say it with the Alef, and Maqas in qaf" (ma?ass is the spoken lexeme for 'scissors' that is written as maqass). Another first grader reported on a lexical difference saying, "Of course there is a difference, we [meaning Arabic Language speakers when conversing in aammyia] use the word "Mehafev" (Computer in Hebrew) but in Arabic fusha we say hasu:b" instead. A second grader expressed similar lexical difference "maealan qubała fusћa" (for example "hat" [MSA] fusha). A second grader presented the vowelization difference between the two language varieties "fi Tabe wfi Tabatan, Tawle wTawIlatan" (meaning "there is a ball" [SA with no vowelization ] and a "ball" [MSA with vowelization], a "table" [SA] and a "table" [MSA]), while a third grader pointed to lexical differences relating to the same lexeme "maealan zaj Tabe wkura" (for example like "ball" [SA] and "ball” [MSA]). Similarly, one fourth grader gave example of a lexical difference kundara (SA for "shoes") and ћIða? (MSA for "shoes"), while another fourth grader pointed to phonological differences, "Pa:l" (SA for "said") and "qa:l” (MSA for "said") referring to the fact that in some Palestinian di- 
alects the Arabic qaf /q/ in MSA is pronounced as a glottal stop / $/$.

When queried about their awareness to similarities between the two language varieties, it was typical for third-fifth graders to acknowledge that there are similarities between the two varieties, which was only an observed variant in first and second grades. Similarly, most of the examples outlined by the participants are related to lexical or phonological features. It was also typical for third-fifth graders to identify that these two language varieties are called Arabic as a similarity feature.

\subsubsection{Categories for Domain 3: Perceived Challenges and Preferences in Processing Fusha}

Participants typically expressed awareness to challenges in perceiving fusha in all grade levels, especially in reading as opposed to listening to fusha. There was also a general report of liking fusha in third through fifth grade levels, which was a typical trend in the responses of first and second graders as well.

When the participants were asked about the process of writing in fusha, third-fifth graders typically reported thinking about the topic first in ammiya and later writing it in fusha.

Differences in text preferences were observed in all grade levels. It was typically reported that participants preferred novels in all grade levels. Variant reports of preferences to reading, poems were also reported by all participants.

\section{Discussion}

The findings of this preliminary study suggest that typically developing Arabic speaking children in Israel develop their meta-diglossic knowledge with age increase where a noticeable improvement in their explicit diglossic knowledge occurs in third grade. This is in the context of mixed towns where Arabic exposure and use in compromised and in the lack of explicit teaching of diglossia and the interrelationship between the two language varieties. Most importantly, a disassociation in the development of diglossic awareness in contrast to text knowledge and cognitive processes awareness was revealed with age/grade increase. We argue that this disassociation signifies that meta- diglossic knowledge is part of advanced language for learning developmental trajectory in the specific sociolinguistic situation of diglossia. Further systematic cross-situational research, (such as in administering the questionnaire to students from different diglossic situations such as Palestinian Arabic speakers in Israel, African American English speakers in the United States, and Cypriot Greek speakers in Cyprus) is needed to enhance our understanding of the development of this knowledge within different contexts.

Most of the differences between the two language varieties outlined by the participants were lexical and phonological in nature. It would be interesting to see how this interrelationship conceptualization develops as age increases and at what stage children address morpho-syntactic differences. Moreover, even though there are typical reports of thinking in SA and writing in MSA, it is interesting to note that only children in third grade and beyond reported this practice and that these practices were not observed to increase with age increase, indicating the possibility they mainly underlined by learning style. Future research should examine the presence and nature of these disassociations within a linguistically informed curriculum.

Recent studies stress the importance of integrating explicit teaching of diglossia and the interrelationship between the two language varieties (For a review see Pearson, Conner, \& Jackson, 2013). This pilot data should be taken into account in assessing language and literacy skills in Arabic diglossia at the elementary school level. We argue that incorporation of this knowledge in language for learning evaluation and intervention is necessary for screening children at risk and for intervention. Moreover, Similar to other oral-litrecay mismatch situations, there is a need to consider the effects of development of linguistically informed educational approaches designed to facilitation of explicit knowledge of diglossia towards academic success (e.g. Pearson et al., 2013) in Arabic. As established in the literature on teaching English for AAE speaking children, we hypothesize that an informed approach toward Arabic teaching would, in turn, generate a supportive educational setting for academic success in which the specific needs of learning to read and write in diglossic situations are addressed. However, the findings of this study show that diglossic knowledge and awareness can develop in the absence of explicit informed teaching of diglossia. Hence, explicit informed teaching is assumed mainly to maximize this awareness towards ultimate readiness to learn read and write in oral-literacy mismatch situations.

Also of interest was that an effect of cultural values was observed in children's responses indicating MSA superiority. It would be interesting to see how these values are shaped within a linguistically informed curriculum that would assign equal values to the two language varieties of Arabic and enable an objective understand- 
ing of the interrelationship between the two linguistic systems, especially in light of the assigned inferior status to Arabic by the Israeli state (e.g. Amara, 2006). We assume this approach would implicitly and explicitly underscore the richness of language variation in Arabic and may increase students' appreciation and interest in learning the language.

\section{Conclusions and Recommendation for Future Research}

Data from the acquisition of Palestinian Arabic indicate, in the same vein with data from several other languages, that at the third grade level, children attain meta-diglossic knowledge in which he/she identifies the two language varieties and the interrelationship between them. Furthermore, this study highlights the need for intensifying cross linguistic/situational research addressing language and literacy development in speech communities exhibiting oral-literacy mismatch situations. These cross-linguistic studies would enhance our understanding of the nature of the relationship among language, literacy and learning. Future studies examining diglossic knowledge and awareness cross linguistically would enable to identify unities and universal milestones within oralliteracy mismatch situations. Lastly, the study provides preliminary findings that should be applied in clinical and educational assessment. There is a need to expand this line of research and examine the development of this specific sociolinguistic skills more intensively (utilizing implicit and explicit measures), while examining larger number of participants from different cities with parametric analysis.

Furthermore, if meta-diglossic knowledge is the foundation skill for successful learning to read and write in diglossic situations, we expect that it would be underdeveloped in children with reading difficulties and impairments. Hence, future examination of the development of diglossic and meta-diglossic knowledge in children with typical development in comparison to children with learning difficulties and impairments is needed to test this hypothesis and examine any potential effects or correlations and/or predictability between decreased metadiglossic awareness and reading success.

\section{Acknowledgements}

Much appreciation and gratitude to Oranim Academic College for funding the research and the publication of it. Ultimately, special thanks to the research team, experts and participating school who have immensely contributed to our research.

\section{References}

Amara, M. H. (2006). Teaching Arabic in Israel. In: K. Wahba, Z. Taha, \& L. England (Eds.), Handbook for Arabic Language Teaching Professionals in the 21st Century (pp. 81-97). Mahwah, New Jersey: Lawrence Erlbaum Associates.

Central Bureau of Statistics (2013). Statistical Abstract of Israel: Population. Jerusalem: The State of Israel.

Coursen-Neff, Z. (2004) Discrimination against Palestinian Arab Children in the Israeli Educational System. New York University Journal of International Law \& Politics, 36, 749-1005.

Craig, H. K., Thompson, C. A., Washington, J. A., \& Potter, S. L. (2003). Phonological Features of Child African American English. Journal of Speech, Language, and Hearing Research, 46, 623-635. http://dx.doi.org/10.1044/1092-4388(2003/049)

Elgibali, A. (1996). Beginning to Understand ARABIC. In: A. Elgibali (Ed.), Understanding Arabic: Essays in Contemporary Arabic Linguistics in Honor of El-Said Badawi (pp. 1-15). Cairo: The American University in Cairo Press.

Ferguson, C. (1959). Diglossia. Word, 15, 325-340.

Goswami, U. (2008). Reading, Dyslexia and the Brain. Educational Research, 50, 135-148. http://dx.doi.org/10.1080/00131880802082625

Harris, Y. R., \& Schroeder, V. M. (2013). Language Deficits or Differences: What We Know about African American Vernacular English in the 21st Century. International Education Studies, 6, 194-204. http://dx.doi.org/10.5539/ies.v6n4p194

Haeri, N. (2003). Sacred Language, Ordinary People: State, Religion, and Modernity in Egypt. New York: Palgrave Macmillan. http://dx.doi.org/10.1057/9780230107373

Holes, C. (2004). Modern Arabic: Structures, Functions, and Varieties (Revised Edition). Washington DC: Georgetown University Press.

Israeli Ministry of Education (2009). Curriculum for Arabic Language Teaching: Language, Literature, and Culture for Elementary School Level (1st-6th Grade). Tel-Aviv: Maalot Publisher. 
Khamis-Dakwar, R., Froud, K., \& Gordon, P. (2012). Acquiring Diglossia: Mutual Influences of Formal and Colloquial Arabic on Children's Grammaticality Judgments. Journal of Child Language, 39, 1-29. http://dx.doi.org/10.1017/s0305000910000784

Khamis-Dakwar, R., \& Makhoul, B. (2014). Arabic Diglossia and Its Implications for Language Learning Disability Assessment. In E. Saiegh-Haddad, \& M. Joshi (Eds.), Arabic Literacy Handbook: Theoretical Insights and Practical Challenges (pp.279-303). Dordrecht and New York: Springer.

Labov, W. (2003). When Ordinary Children Fail to Read. Reading Research Quarterly, 38, 128-131.

Leikin, M., Ibrahim, R., \& Eghbaria, H. (2013). The Influence of Diglossia in Arabic on Narrative Ability: Evidence from Analysis of the Linguistic and Narrative Structure of Discourse among Pre-School Children. Reading and Writing, 27, 733-747. http://link.springer.com/article/10.1007/s11145-013-9462-3

Pearson, B. Z., Conner, T., \& Jackson, J. E. (2013). Removing Obstacles for African American English Speaking Children through Greater Understanding of Language Difference. Developmental Psychology, 49, 31-44. http://dx.doi.org/10.1037/a0028248

Pittas, E., \& Nunes, T. (2014). Dialect Awareness and Literacy in Bidialectal Setting. Hellenic Journal of Psychology, 11, 56-82.

Roseberry-McKibbin, C. (2008). Multicultural Students with Special Language Needs. Oceanside, CA: Academic Communication Association.

Saiegh-Haddad, E. (2003). Linguistic Distance and Initial Reading Acquisition: The Case of Arabic Diglossia. Applied Psycholinguistic, 24, 115-135. http://dx.doi.org/10.1017/s0142716403000225

Saiegh-Haddad, E. (2004). The Impact of Phonemic and Lexical Distance on the Phonological Analysis of Words and Pseudowords in a Diglossic Context. Applied Psycholinguistics, 25, 495-512. http://dx.doi.org/10.1017/S0142716404001249

Saiegh-Haddad, E. (2005). Correlates of Reading Fluency in Arabic Diglossic and Orthographic Factors. Reading and Writing, 18, 559-582. http://dx.doi.org/10.1007/s11145-005-3180-4

Saiegh-Haddad, E., Hende, N., \& Ziv, M. (2012). The Linguistic Affiliation Constraint and Phoneme Recognition in Diglossic Arabic. Journal of Child Language, 38, 297-315. http://dx.doi.org/10.1017/S0305000909990365

Saiegh-Haddad, E., \& Henkin-Roitfarb, R. (2014). The Structure of Arabic Language and Orthography. In E. Saiegh-Haddad, \& M. Joshi (Eds.), Handbook of Arabic Literacy: Insights and Perspectives (pp. 3-28). Dordrecht: Springer. http://dx.doi.org/10.1007/978-94-017-8545-7_1

Terry, N. P., Connor, C. M., Thomas-tate, S., \& Love, M. (2010). Examining Relationships among Dialect Variation, Literacy Skills, and School Context in First Grade. Journal of Speech, Language, and Hearing Research, 53, 126-145. http://dx.doi.org/10.1044/1092-4388(2009/08-0058)

Terry, N. P., \& Scarborough, H. S. (2011). The Phonological Hypothesis as a Valuable Framework for Studying the Relationship of Dialect Variation to Early Reading Skills. In S. Brady, D. Braze, \& C. A. Fowler (Eds.), Explaining Individual Differences in Reading: Theory and Evidence (pp. 97-117). New York: Psychology Press.

Thompson, C. A., Craig, H. K., \& Washington, J. A. (2004). Variable Production of African American English across Oracy and Literacy Contexts. Language, Speech, and Hearing Services in Schools, 35, 269-282.

http://dx.doi.org/10.1044/0161-1461(2004/025)

Willis, W. (2004). Families with African American Roots. In E. Lynch, \& M. Hanson (Eds.), Developing Cross-Cultural Competence (3rd ed., pp.141-178). Baltimore, MD: Paul Brooks. 


\section{Appendix 1 ADAT: Task 1}

Diglossic knowledge and awareness subtest.

\begin{tabular}{|c|c|c|c|c|}
\hline & Question & NA/0 & 1 & 2 \\
\hline \multirow{2}{*}{ 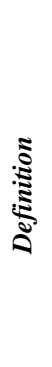 } & $\begin{array}{l}\text { Q1: Do you know that in Arabic there is } \\
\text { a fusha and ammiya, what are these } \\
\text { two? }\end{array}$ & $\begin{array}{l}\text { is No answer/ unable to explain } \\
\text { about fusha or ammiya }\end{array}$ & $\begin{array}{l}\text { explains about one variety and } \\
\text { its use }\end{array}$ & $\begin{array}{l}\text { explains about the } \\
\text { context of use of the two } \\
\text { varieties OR the } \\
\text { interrelationship between } \\
\text { fusha and ammiya }\end{array}$ \\
\hline & $\begin{array}{l}\text { Q2: When do we use each one of those? } \\
\text { can you give me an example of when } \\
\text { do you use fusha and when do you use } \\
\text { ammiya }\end{array}$ & $\begin{array}{l}\text { ? Does not know when the two } \\
\text { varieties are used }\end{array}$ & $\begin{array}{l}\text { Explains the contexts of use } \\
\text { for one variety only OR } \\
\text { provides only examples but } \\
\text { does not explain relationship }\end{array}$ & $\begin{array}{l}\text { Explains the contexts of } \\
\text { use for the two varieties } \\
\text { with/without examples }\end{array}$ \\
\hline \multirow{2}{*}{ 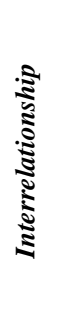 } & $\begin{array}{l}\text { Q3: Is there any differences between } \\
\text { these two languages? Can you give } \\
\text { some examples?, }\end{array}$ & $\begin{array}{l}\text { The child does not know there } \\
\text { are differences between the two } \\
\text { varieties }\end{array}$ & $\begin{array}{l}\text { The child talks about the } \\
\text { differences or provided } \\
\text { example/s of the differences }\end{array}$ & $\begin{array}{l}\text { The child knows the } \\
\text { differences between the } \\
\text { two varieties with } \\
\text { examples }\end{array}$ \\
\hline & $\begin{array}{l}\text { Q4: Are there any common things } \\
\text { between the two languages? Can you } \\
\text { give me some examples? }\end{array}$ & $\begin{array}{l}\text { The child does not report } \\
\text { knowing there are similarities } \\
\text { between the two varieties }\end{array}$ & $\begin{array}{l}\text { The child talks about the } \\
\text { similarities or provides } \\
\text { example of the similarities }\end{array}$ & $\begin{array}{l}\text { The child knows the } \\
\text { similarities between the } \\
\text { two varieties with } \\
\text { examples }\end{array}$ \\
\hline 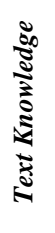 & $\begin{array}{l}\text { Q5 } \\
\text { Which texts do you like to read? } \\
\text { If the child is unable to name favorite } \\
\text { text types, prompt him/her as follows: } \\
\text { Do you like reading stories, scientific } \\
\text { articles, or poems }\end{array}$ & $\begin{array}{l}\text { The child does not identify } \\
\text { favorite text types of text after } \\
\text { explanation provided }\end{array}$ & $\begin{array}{l}\text { The child knows which type } \\
\text { of texts he likes only with } \\
\text { prompting }\end{array}$ & $\begin{array}{l}\text { The child knows exactly } \\
\text { which type of texts } \\
\text { he/she likes }\end{array}$ \\
\hline \multirow{3}{*}{ 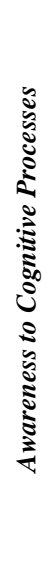 } & $\begin{array}{l}\text { Q6 Do you at times feel it is hard for } \\
\text { you to understand fusha? } \\
\text { If the child reports it's hard for him/her } \\
\text { to understand fusha - ask the following: } \\
\text { Is it harder for you when you hear it or } \\
\text { when you read it }\end{array}$ & $\begin{array}{l}\text { The child reports awareness to } \\
\text { the challenges processing fusha } \\
\text { but reports good ability to using } \\
\text { : it }\end{array}$ & $\begin{array}{l}\text { The child reports difficulty } \\
\text { understanding fusha with } \\
\text { awareness to challenges in } \\
\text { processing it in light of } \\
\text { diglossia }\end{array}$ & $\begin{array}{l}\text { The child reports no } \\
\text { challenges with no } \\
\text { awareness to the } \\
\text { potential effects of } \\
\text { diglossia }\end{array}$ \\
\hline & $\begin{array}{l}\text { Q7: Do you like writing in fusha or just } \\
\text { speaking it, }\end{array}$ & None & Writing OR Speaking & Both \\
\hline & $\begin{array}{l}\text { Q8: When you are about to write about } \\
\text { a specific topic, do you think about the } \\
\text { topic in fusha and write it directly in } \\
\text { fusha or do you think about the topic } \\
\text { first in ammiya and later writing it in }\end{array}$ & $\begin{array}{l}\text { Thinks in ammiya and writes in } \\
\text { ammiya OR can write in fusha } \\
\text { OR unaware of the processing } \\
\text { involved in writing fusha }\end{array}$ & $\begin{array}{l}\text { Thinks in ammiya and then } \\
\text { writes it down in fusha }\end{array}$ & $\begin{array}{l}\text { Thinks and writes } \\
\text { directly in fusha }\end{array}$ \\
\hline
\end{tabular}

